\title{
Article \\ Cross-Linking Combined with Surfactant Bilayer Assembly Enhances the Hydrophilic and Antifouling Properties of PTFE Microfiltration Membranes
}

\author{
Shijie Xu ${ }^{1}$, Wenzhong Ma ${ }^{1,2,3, *}$, , Haicun Yang ${ }^{1}$, Zheng Cao ${ }^{1}$, Fanghong Gong ${ }^{1}$ and Chunlin Liu ${ }^{1,2}$ \\ 1 Jiangsu Key Laboratory of Environmentally Friendly Polymeric Materials, School of Materials Science and \\ Engineering, Jiangsu Collaborative Innovation Center of Photovoltaic Science and Engineering, Changzhou \\ University, Changzhou 213164, China; xsj19970126@163.com (S.X.); yhcbobo@cczu.edu.cn (H.Y.); \\ zcao@cczu.edu.cn (Z.C.); fhgong@cczu.edu.cn (F.G.); chunlin@cczu.edu.cn (C.L.) \\ 2 Huaide College, Changzhou University, Jingjiang 214500, China \\ 3 National Experimental Demonstration Center for Materials Science and Engineering, Changzhou University, \\ Changzhou 213164, China \\ * Correspondence: wenzhong-ma@cczu.edu.cn
}

Citation: Xu, S.; Ma, W.; Yang, H.;

Cao, Z.; Gong, F.; Liu, C.

Cross-Linking Combined with

Surfactant Bilayer Assembly

Enhances the Hydrophilic and

Antifouling Properties of PTFE

Microfiltration Membranes.

Separations 2022, 9, 2. https://

doi.org/10.3390/separations9010002

Academic Editor: Pavel

Nikolaevich Nesterenko

Received: 19 November 2021

Accepted: 15 December 2021

Published: 22 December 2021

Publisher's Note: MDPI stays neutral with regard to jurisdictional claims in published maps and institutional affiliations.

Copyright: (c) 2021 by the authors. Licensee MDPI, Basel, Switzerland. This article is an open access article distributed under the terms and conditions of the Creative Commons Attribution (CC BY) license (https:// creativecommons.org/licenses/by/ $4.0 /)$.

\begin{abstract}
The inherent strong hydrophobicity of Polytetrafluoroetylene (PTFE) microfiltration membranes results in low separation efficiency and easy contamination. In order to enhance its hydrophilic and antifouling properties, we first modified the PTFE microfiltration membrane by using Polyethylene glycol laurate (PEGML) for first layer deposition and then used Polyvinyl alcohol (PVA)/citric acid (CA) cross-linked coatings for second layer deposition. The Scanning Electron Microscope (SEM) results showed that the fibers and nodes of the modified PTFE microfiltration membrane were coated with PVA/CA hydrophilic coating. FT-IR Spectromete and X-ray photoelectron spectrometer (XPS) analysis results confirmed that crosslinking of PVA and CA occurred and that PEGML and PVA/CA were successfully deposited onto the membrane surface. The modification conditions were optimized by hydrophilicity testing, and the best hydrophilicity of the modified membrane was achieved when the crosslinking content of PEGML was $2 \mathrm{~g} \cdot \mathrm{L}^{-1}$, PVA was $5 \mathrm{~g} \cdot \mathrm{L}^{-1}$, and CA was $2 \mathrm{~g} \cdot \mathrm{L}^{-1}$. PTFE microfiltration membranes modified by the optimal conditions achieved a water flux of $396.9 \mathrm{~L} \cdot \mathrm{m}^{-2} \cdot \mathrm{h}^{-1}$ (three times that of the original membrane) at low operating pressures $(0.05 \mathrm{MPa})$, and the contact angle decreased from $120^{\circ}$ to $40^{\circ}$. Meanwhile, the modified PTFE microfiltration membrane has improved contamination resistance and good stability of the hydrophilic coating.
\end{abstract}

Keywords: PTFE microfiltration membranes; hydrophilic; antifouling properties; polyvinyl alcohol; cross-linking

\section{Introduction}

PTFE microfiltration membrane has the advantages of acid and alkali resistance, high and low-temperature resistance, microbial infestation resistance, oil and pressure resistance, and low surface friction coefficient. It is an ideal filtration material for separation. PTFE microfiltration membranes have been successfully and extensively used in Membrane bioreactor technology to treat domestic wastewater and oil-water separation [1-5]. However, the highly symmetrical structure and extremely low surface energy of PTFE itself results in strong hydrophobicity, which limits its application in the field of water filtration. The strong hydrophobicity of polytetrafluoroethylene makes it difficult for water to penetrate into membrane pores; thus, a high operating pressure is required, and this results in low flux. At the same time, due to the strong hydrophobic interaction between PTFE and hydrophobic solutes in water, PTFE membranes are easily contaminated. The construction of hydrophilic interfaces on the membrane surface is considered a general method for effectively avoiding or mitigating the adsorption or deposition of contaminants on the membrane surface [6]. Membrane surfaces with hydrophilic properties can interact 
with water molecules to form a hydrated layer, thus enhancing antifouling ability and separation efficiency of the filter membrane [7].

In the past few decades, people have performed a lot of work for the hydrophilic modification of PTFE surface, such as plasma treatment, wet chemical treatment, and radiation modification, etc. [8-10]. The advantage of this type of modification is that the hydrophilicity of the modified PTFE membrane is enhanced, and wettability can be maintained for an extended period. However, it also has disadvantages, such as possible damage to the molecular structure and morphology of the membrane surface. At the same time, plasma modification and radiation modification require expensive equipment support, and the waste liquid generated by chemical treatment is challenging to treat and easily pollutes the environment [11]. Therefore, these methods are difficult to realize with respect to application in industries.

In recent years, the cross-linked co-deposition method has received much attention in the modification of PTFE microfiltration membranes due to its simplicity, low cost, and ease of industrialization. This method usually involves depositing and wrapping a hydrophilic layer onto the fibers and nodes of the PTFE microfiltration membrane by crosslinking one or more hydrophilic substances [12-14]. Polyvinyl alcohol is an environmentally friendly material with abundant hydroxyl groups in its molecular chain and good hydrophilic and biocompatible properties. Polyvinyl alcohol has been widely used for hydrophilic modification of polymeric membranes. Polyvinyl alcohol can be deposited on the surface of the membrane to form a microgel coating, which has an important influence on the performance of the separation membrane [15]. Crosslinking can adjust the performance of the microgel coating, such as improving its solvent resistance, stability in water, and effectively preventing its plasticization [16-18]. For polyvinyl alcohol, crosslinking is also needed to improve its stability in the water phase. Yu Gu et al. used PVA solution to coat PVDF microporous membrane and then used irradiation to crosslink PVA coated on the membrane's surface. The modified Polyvinylidene Fluoride (PVDF) microporous membrane has good oil-water separation performance. However, the expensive irradiation equipment still limits its application in industrial production [19]. Chengcai Li et al. codeposited a crosslinked PVA layer on the PTFE membrane surface, followed by in situ embedded $\mathrm{SiO}_{2}$ nanoparticle adhesion for the secondary hydrophilic treatment of PTFE membranes. The results showed that the treated membranes had good hydrophilic and antibacterial properties [20]. Kunpeng Wang et al. used PVA as a hydrophilic coating and glutaraldehyde as a cross-linking agent to prepare a hydrophilic coating on the PTFE surface by electrostatic spinning. The study showed that the PVA crosslinked coating could effectively prevent the PTFE membrane from oil contamination [21]. However, crosslinking agents such as epichlorohydrin and glutaraldehyde have certain biological toxicity, which affects the application of PTFE microfiltration membranes in food filtration, medical utilization, and other fields. Shafei et al. prepared a PVA coating on the surface of the nanocomposite membrane by a coating process and crosslinked it using glutaraldehyde. Their study showed that the antifouling ability of the nanocomposite membrane was enhanced after coating with PVA, and the retention of Congo red dye could reach more than 98\% [22]. Citric acid is a green food additive that can be crosslinked with PVA catalyzed by high temperatures above $100^{\circ} \mathrm{C}$, providing a new idea for green crosslinking PVA [23].

The wetting behavior of surfactant solutions on hydrophobic surfaces has a crucial role in surface interface science. Adsorption of surfactants at the gas-liquid interface is an effective method for reducing surface tension of liquids, resulting in better wetting of solids by liquids [24]. The wetting behavior of different surfactants on PTFE surfaces has been extensively studied, and the wettability of PTFE microporous membranes can be enhanced by simple surfactant adsorption [25-27]. Polyethylene glycols are widely used in the hydrophilic modification of membranes and in constructing antifouling interfaces because of their excellent hydration capacity and anti-protein properties [28,29]. Polyethylene glycol laurate (PEGML) is a polyethylene glycol-derived nonionic surfactant that is widely 
used in industries because of its low price, low toxicity, volatility, and biodegradability [30]. At the same time, it can be deposited onto the PTFE membrane surface by hydrophobic interactions and van der Waals forces. However, the wettability from surfactant treatment alone is not long lasting [31].

We use a combination of surfactants and cross-linked co-deposition double-layer self-assembly method to hydrophilize the PTFE microfiltration membrane. In this paper, the PTFE membrane is pretreated by a PEGML solution in order to reduce its surface tension and initially enhance the wettability of the PTFE microfiltration membrane. In order to better anchor PEGML to the membrane surface, we used PVA and green non-toxic CA crosslinked to form a three-dimensional network structure with hydrophilic groups deposited and wrapped around the fibers and nodes of the membrane. SEM, FTIR, and XPS characterized the chemical composition and microstructure of the modified PTFE microfiltration membranes. At the same time, the modification conditions were optimized, and the anti-pollution properties and hydrophilic coating stability of the modified membranes were investigated.

\section{Materials and Methods}

\subsection{Materials}

PTFE flat microfiltration membrane $(0.22 \mu \mathrm{m}$, Support is PET non-woven fabric) was provided by Changzhou Jinchun Environmental Protection Technology Co., Ltd. (Changzhou, China). Polyvinyl alcohol (Mw:65742; D:2.48018) was provided by Sinopec Great Wall Energy \& Chemical Co., Ltd. (Lingwu, China). Citric acid (AR) was purchased from Xinxing Chemical Reagent Co., Ltd. (Hefei, China). Polyethylene glycol monolaurate (AR) was purchased from Shanghai Macklin Biochemical Co., Ltd. (Shanghai, China). Anhydrous ethanol (AR), bovine serum protein (AR), disodium hydrogen phosphate (AR), and sodium dihydrogen phosphate (AR) were purchased from Sinopharm Chemical Reagent Co., Ltd. (Shanghai, China). Distilled water is homemade at a laboratory. All reagents were used without further purification.

\subsection{Preparation of PTFE-Modified Membranes}

The PTFE microfiltration membrane was first soaked in ethanol and shaken in ultrasound for $30 \mathrm{~min}$ for washing to remove impurities from membrane pores. The washed PTFE microfiltration membrane is then dried.

The aqueous solution of PVA was obtained by dissolving the polymer in distilled water and stirred at $95^{\circ} \mathrm{C}$ for $3 \mathrm{~h}$. Then, different concentrations of $\mathrm{CA}$ aqueous solution were added to the PVA aqueous solution and mixed well. The PTFE microfiltration membranes were pre-wetted with different concentrations of PEGML ethanol solutions for $30 \mathrm{~min}$. The pre-wetted PTFE membrane was added to the freshly prepared mixed solution for $30 \mathrm{~min}$ of impregnation coating. After coating, the film is taken out and placed into a vacuumdrying oven at $50^{\circ} \mathrm{C}$ for $12 \mathrm{~h}$ and finally cured in a blast drying oven at $130^{\circ} \mathrm{C}$ for $30 \mathrm{~min}$ to achieve crosslinking [32]. After the reaction is completed, the PTFE microfiltration membrane was thoroughly washed with deionized water until the water was close to neutral. Transfer the membrane to a vacuum drying oven at $40{ }^{\circ} \mathrm{C}$ and remove it to obtain a hydrophilized modified PTFE microporous membrane. This series of modified films is named M-PEGML_/PVA_/CA_. Moreover, we prepared PTFE microfiltration membranes modified with PVA/CA coating after pre-wetting using ethanol solution as a comparison group. This series of modified films was named M-PVA_/CA . In addition, in order to optimize hydrophilic modification conditions, membranes pretreated with PEGML only and membranes coated with PVA solution after pre-wetting with ethanol were prepared. These two series of membranes were named M-PEGML_ and M-PVA_, respectively. The preparation conditions for all samples were recorded in Table 1. 
Table 1. Modification conditions of different PTFE microfiltration membranes.

\begin{tabular}{cccc}
\hline Code Name & PEGML $\left(\mathbf{g} \cdot \mathbf{L}^{-\mathbf{1}}\right)$ & PVA $\left(\mathbf{g} \cdot \mathbf{L}^{-\mathbf{1}}\right)$ & CA(g. $\left.\mathbf{L}^{-\mathbf{1}}\right)$ \\
\hline M & 0 & 0 & 0 \\
M-PEGML1 & 1 & 0 & 0 \\
M-PEGML2 & 2 & 0 & 0 \\
M-PEGML3 & 3 & 0 & 0 \\
M-PEGML4 & 4 & 0 & 0 \\
M-PEGML5 & 5 & 0 & 0 \\
M-PVA5 & 0 & 5 & 0 \\
M-PVA10 & 0 & 10 & 0 \\
M-PVA15 & 0 & 15 & 0 \\
M-PVA20 & 0 & 20 & 0 \\
M-PEGML2/PVA5/CA1 & 2 & 5 & 1 \\
M-PEGML2/PVA5/CA2 & 2 & 5 & 2 \\
M-PEGML2/PVA5/CA3 & 2 & 5 & 4 \\
M-PEGML2/PVA5/CA4 & 2 & 5 & 5 \\
M-PEGML2PVA5/CA5 & 2 & 5 & 2 \\
M-PVA5/CA2 & 0 & 5 & 4 \\
\hline
\end{tabular}

M-PEGML indicates the sample after pre-wetting with PEGML solution. M-PVA indicates the sample coated with PVA after pre-wetting with ethanol. M-PEGML/PVA/CA indicates samples pretreated with PEGML solution and then coated with PVA/CA. M-PVA/CA indicates samples pre-wetted with ethanol and then coated with PVA/CA.

The process of hydrophilic modified PTFE microfiltration membrane is shown in Figure 1a. The scheme of green crosslinking of PVA and CA at $130^{\circ} \mathrm{C}$ is shown in Figure $1 \mathrm{~b}$.

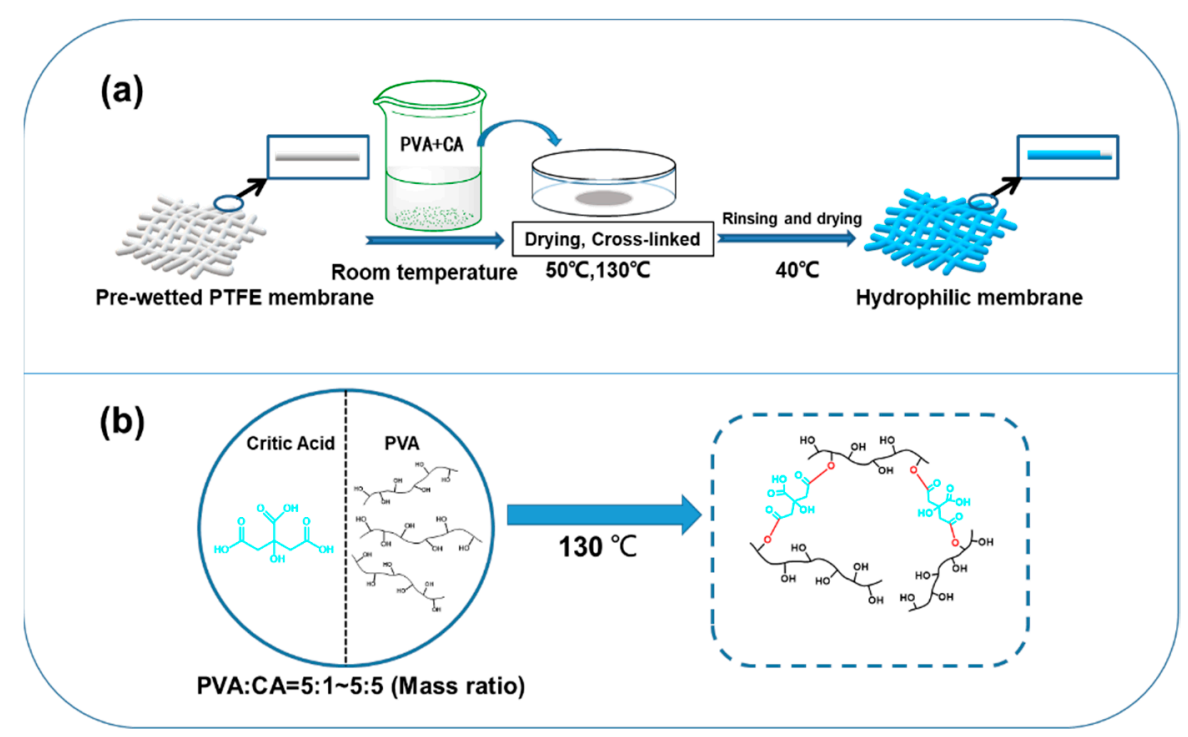

Figure 1. (a) The illustration of a hydrophilic modification of the PTFE microfiltration membrane. (b) The scheme of the green cross-linking mechanism of PVA and CA at $130{ }^{\circ} \mathrm{C}$.

\subsection{Characterization of PTFE Microfiltration Membrane Structure and Surface Chemical Composition}

The surface morphology of the PTFE microfiltration membrane before and after modification was observed by scanning electron microscope (JMA-5610LV, JEOL, Tokyo, Japan). Surface roughness of PTFE microfiltration membrane before and after modification was examined using laser confocal microscopy (OLS4100, Olympus, Tokyo, Japan). Analysis of the changes in groups and chemical composition of the membrane surface before and after modification was examined by using FT-IR (Nicolet iS50, Thermo Fisher Company, IA, USA) spectroscopy and XPS (ESCALAB 250XI, Thermo Fisher Company, IA, USA). 


\subsection{Surface Wettability and Pure Water Flux Testing of PTFE Microfiltration Membranes}

The wettability of a membrane is characterized by the water contact angle of the membrane surface. The water contact angle is measured by a contact angle goniometer (DSA100, KRUSS, Hamburg, Germany) on the membrane before and after modification. A membrane is attached to a slide and mounted on the goniometer. A drop of distilled water $(2 \mu \mathrm{L})$ is applied to the membrane surface at room temperature. The contact angle value is obtained as the average of five measurements. Each reported a reliable value as the average of five measurements. The variation of the contact angle of water drops on the membrane surface with time was also measured by using the automatic screenshot function of the contact angle instrument with a $10 \mathrm{~s}$ interval.

The pure water flux of the PTFE microfiltration membrane was tested using staggered flow filtration equipment (SF-MA, Hangzhou Saifei Membrane Separation Technology Co., Hangzhou, China). The $\mathrm{M}_{0}$ membrane was pre-wetted in ethanol for $0.5 \mathrm{~h}$ before testing, and then the pre-wetted membrane was washed in distilled water for $2 \mathrm{~h}$. All the modified membranes were tested directly. Each membrane was filtered with distilled water at a pressure of $0.1 \mathrm{MPa}$ for at least $60 \mathrm{~min}$ before testing in order to ensure a stable flux. Then, the pure water flux of the membrane was tested at a transmembrane pressure of $0.05 \mathrm{MPa}$. Each reported reliable flux result is the average of three measurements. The water flux $\left(J_{W}\right)$ is calculated from Equation (1):

$$
J_{W}=\frac{V}{A \times \Delta t}
$$

where $J_{W}$ is the volumetric permeate water flux $\left(\mathrm{L} \cdot \mathrm{m}^{-2} \cdot \mathrm{h}^{-1}\right), A$ is the effective permeate area of the membrane $\left(\mathrm{m}^{2}\right)$, and $V$ is the permeate volume (L) during the time interval $\Delta t(\mathrm{~h})$.

\subsection{Anti-Fouling Performance Test of PTFE Microfiltration Membrane}

The antifouling performance of the membranes was evaluated by staggered-flow filtration experiments at $\mathrm{pH}=7.4$ and $25^{\circ} \mathrm{C}$ using an aqueous Bovine serum albumin (BSA) solution as a contaminant model. The concentration of BSA in the feed solution was $0.5 \mathrm{~g} \cdot \mathrm{L}^{-1}$. Prior to measurement, the modified membranes were pretreated with deionized water at $0.1 \mathrm{MPa}$ for at least $60 \mathrm{~min}$ to ensure stable membrane flux $\left(J_{W 0}\right)$. The membrane was then filtered with BSA solution at $0.05 \mathrm{MPa}$ for $90 \mathrm{~min}$. The steady-state fluxes were recorded as $J_{W S}$. Afterward, the contaminated membranes were washed with de-distilled water at $0.1 \mathrm{MPa}$ for $30 \mathrm{~min}$ in order to remove BSA molecules that were loosely deposited on the membrane's surface. After rinsing, continue to test the pure water flux of the membrane, and the pure water flux after stabilization is recorded as the recovery flux $\left(J_{W R}\right)$. The three anti-fouling performance parameters of PTFE microfiltration membranes are calculated as follows.

$$
\begin{gathered}
\text { FRR }(\%)=\frac{J_{W R}}{J_{W 0}} \\
\operatorname{DRt}(\%)=\frac{J_{W 0}-J_{W S}}{J_{W 0}} \\
\operatorname{DRir}(\%)=\frac{J_{W 0}-J_{W R}}{J_{W 0}}
\end{gathered}
$$

The antifouling performance of the prepared membranes was evaluated by three antifouling parameters: flux recovery rate (FRR), total flux decline rate (DRt), and reversible flux decline rate (DRir).

The BSA adsorption test evaluated the static anti-fouling ability of the PTFE microfiltration membrane. PTFE microfiltration membranes were made into $2 \times 2 \mathrm{~cm}^{2}$ size and then immersed in $1 \mathrm{~g} \cdot \mathrm{L}^{-1}$ BSA solution for $12 \mathrm{~h}$. After $12 \mathrm{~h}$ of impregnation, the samples were removed, and the concentration $\left(C_{1}\right)$ of the remaining BSA solution was analyzed by 
UV spectrophotometer, and the adsorption amount of BSA by PTFE membrane before and after modification was calculated using Equation (5):

$$
\text { Adsorption capacity }=\frac{\left(C_{0}-C_{1}\right) \times V}{A}
$$

where $C_{0}$ is the initial concentration of BSA solution $\left(\mathrm{g} \cdot \mathrm{L}^{-1}\right), \mathrm{C}_{1}$ is the concentration of BSA solution after adsorption $\left(\mathrm{g} \cdot \mathrm{L}^{-1}\right), V$ is the volume of BSA solution $(\mathrm{L})$, and $A$ is the sample membrane area $\left(\mathrm{m}^{2}\right)$.

\section{Results}

\subsection{Surface Chemical Composition and Microscopic Morphology Analysis \\ 3.1.1. FTIR Analysis}

Figure 2 shows the infrared spectra of the PTFE microporous membrane before and after modification. From Figure $2 \mathrm{a}$, it can be observed that the $\mathrm{M}_{0}$ microporous membrane only has strong C-F bond stretching vibration peaks at $1210 \mathrm{~cm}^{-1}$ and $1154 \mathrm{~cm}^{-1}$. Figure $2 \mathrm{~b}$ is the infrared spectrum of the M-PVA5 membrane. The broad peak near $3347 \mathrm{~cm}^{-1}$ is the -OH stretching vibration peak, which indicates the attachment of PVA to the surface of the original PTFE membrane and the introduction of the hydrophilic group -OH. In Figure 2c, the M-PVA5/CA2 membrane presents - $\mathrm{OH}$ stretching vibration peaks at $3347 \mathrm{~cm}^{-1}$ and the stretching vibration peak of ester carbonyl $(\mathrm{C}=\mathrm{O})$ at $1721 \mathrm{~cm}^{-1}$, which indicates the cross-linking reaction between PVA and CA [33] and the deposition of PVA/CA cross-linked coating onto the membrane surface. Meanwhile, compared with M-PVA5/CA2, M-PEGML2/PVA5/CA2 has three new characteristic peaks at $2926 \mathrm{~cm}^{-1}, 2850 \mathrm{~cm}^{-1}$, and $1462 \mathrm{~cm}^{-1}$, which are the characteristic absorption peaks of $-\mathrm{CH}_{2}$ asymmetric and symmetric stretching vibrations and $-\mathrm{CH}_{2}$ antisymmetric deformation vibrations on the hydrophobic chain segment of PEGML, respectively. The stretching vibration peaks of $-\mathrm{OH}$ and ester carbonyl $(\mathrm{C}=\mathrm{O})$ were still observed. This illustrates that PEGML and PVA/CA cross-linked coatings were successfully deposited on the surface of PTFE microfiltration membranes.



Figure 2. Infrared spectra of different PTFE microfiltration membranes: (a) $\mathrm{M}_{0}$; (b) M-PVA5; (c) M-PVA5/CA2; (d) M-PEGML2/PVA5/CA2.

\subsubsection{SEM Analysis}

Figure 3 shows the SEM images of the PTFE microporous membrane before and after modification. Figure 3a shows that the $\mathrm{M}_{0}$ membrane has an apparent "fiber-node" structure with uniform distribution of membrane pores and smooth fiber and node surfaces. Figure $3 b$ shows the SEM image of M-PVA5, which shows that the "fiber-node" structure is still present, the pore size is reduced compared to the original membrane. The surface 
of the M-PVA5 membrane fibers and nodes became rougher due to PVA deposition on the fibers and nodes of the membrane after coating. Figure $3 c$ shows the SEM image of the M-PVA5/CA2 modified membrane, from which it can be observed that the gel coating formed by crosslinking of PVA and CA was deposited and wrapped around the fibers and nodes of the PTFE microfiltration membrane. In Figure 3d, the M-PEGML2 membrane has the "fiber-node" structure of the microfiltration membrane. As shown in Figure 3e, the average pore size of the M-PEGML4 microfiltration membrane decreased, which was caused by more PEGML adsorbed on the fibers and nodes of the PTFE microfiltration membrane. Figure $3 \mathrm{f}$ shows that the hydrophilic coated layer on the fibers and nodes of the M-PEGML2/PVA5/CA2 microfiltration membrane is more uniform compared with Figure 3b,c. This is because the surfactant adsorbed on the surface of the film can reduce the surface tension of the coating solution so that the PVA/CA mixed solution spreads evenly on the surface of the film.

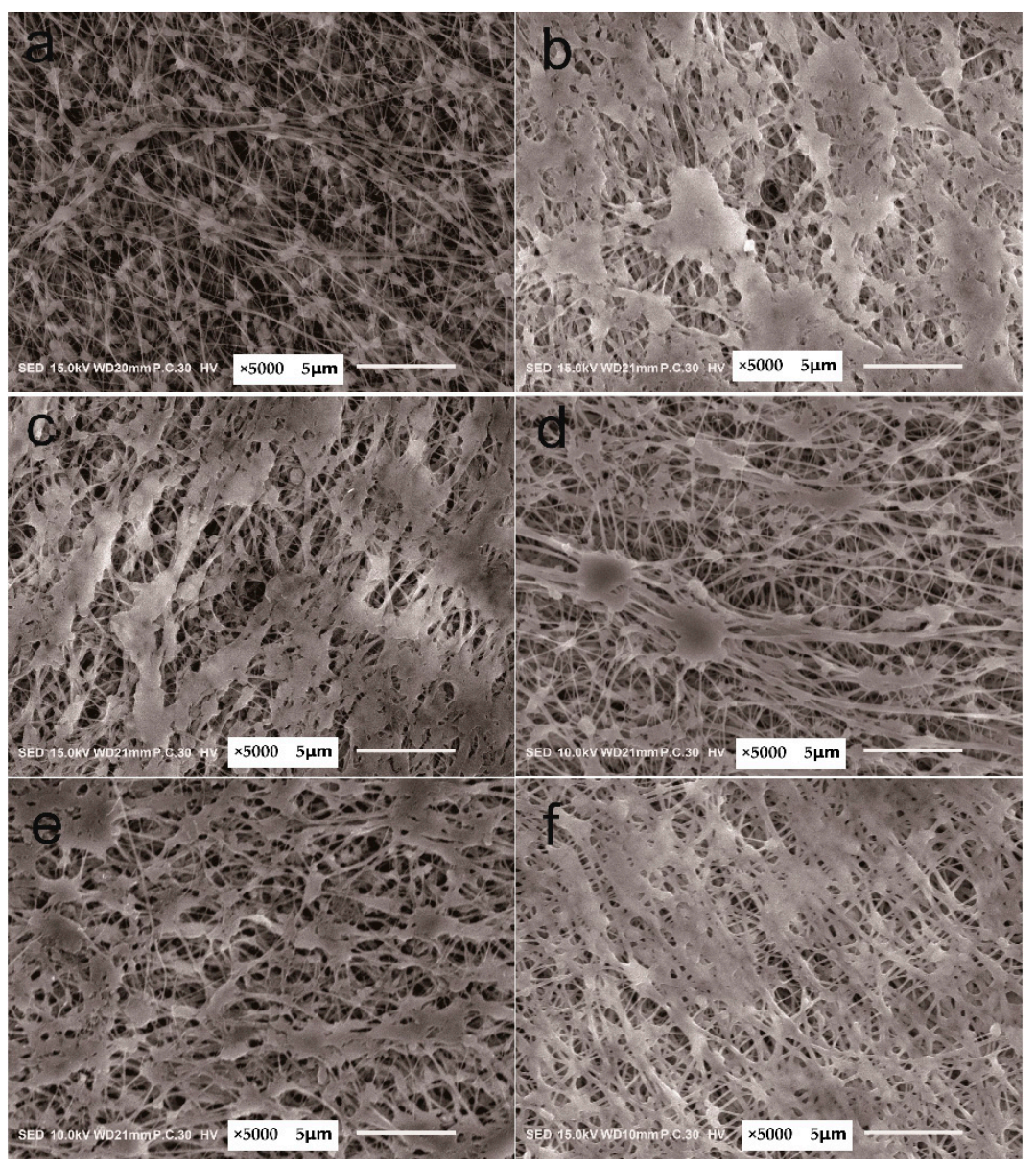

Figure 3. SEM images of the surfaces of different PTFE microfiltration membranes ((a): $\mathrm{M}_{0}$; (b): M-PVA5; (c): M-PVA5/CA2; (d): M-PEGML2; (e): M-PEGML4; (f): M-PEGML2/PVA5/CA2).

\subsubsection{Surface Roughness Analysis}

Figure 4 shows the three-dimensional scanned images of different PTFE microfiltration membranes recorded by Laser Scanning Confocal Microscopy. The root-average roughness and root-average arithmetic roughness of each microfiltration membrane are obtained in Table 2. The surface roughness of the modified M-PVA5, M-PVA5/CA2, and M-PEGML2/PVA5/CA2 was higher compared to the $\mathrm{M}_{0}$ membrane. The increased roughness of the membrane surface was a result of the hydrophilic coating deposited on the PTFE microfiltration membrane surface after modification by different methods. Moreover, the surface roughness of M-PEGML2/PVA5/CA2 was reduced compared with M-PVA5 and M-PVA5/CA2. The decreased surface roughness may be due to the pre-adsorption of PEGML 
on the membrane surface, which allowed the PVA/CA blend to coat the membrane surface more uniformly. This is also consistent with the results observed by SEM.

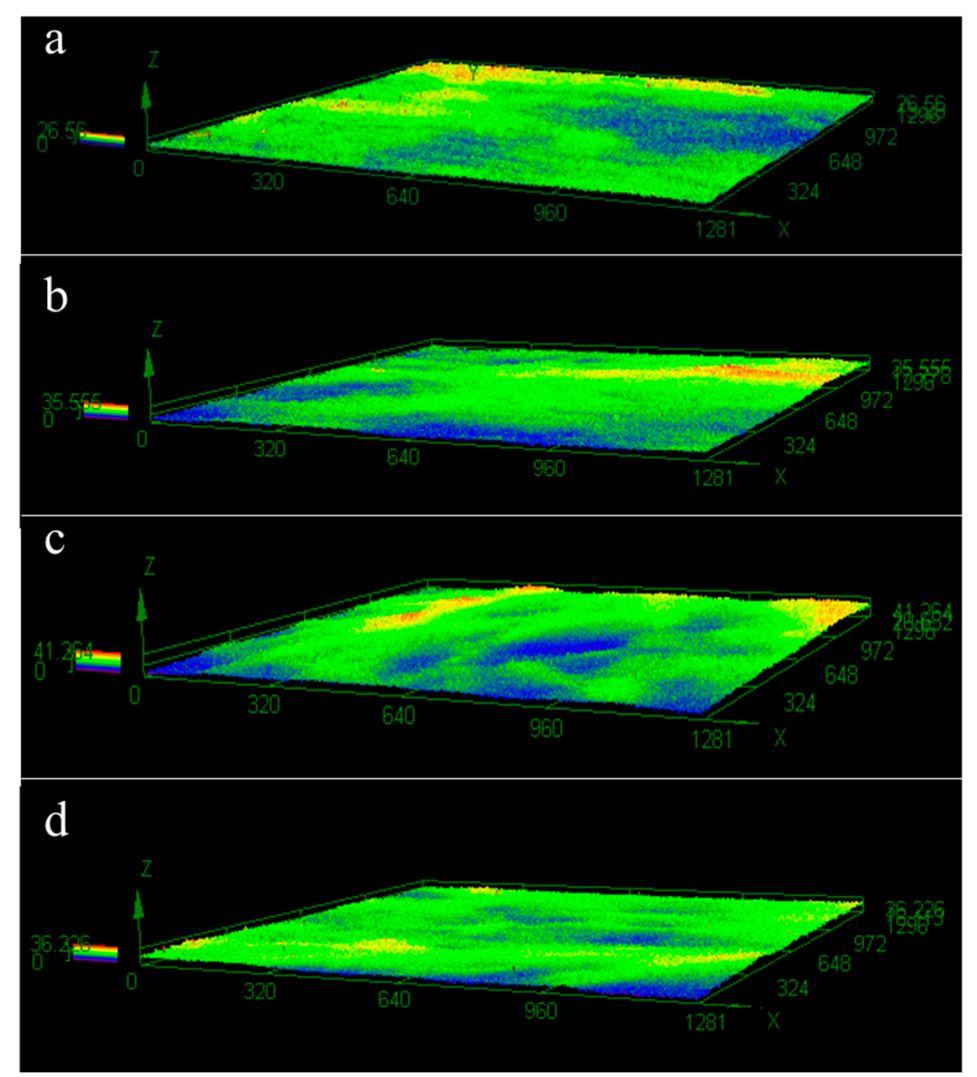

Figure 4. Surface morphology images of different PTFE microfiltration membranes ((a): $\mathrm{M}_{0}$; (b): M-PVA5; (c): M-PVA5/CA2; (d): M-PEGML2/PVA5/CA2).

Table 2. Sq (Standard deviation of asperity height) and Sa (Mean height of asperity) values of different PTFE microfiltration membranes.

\begin{tabular}{ccc}
\hline Samples & Sq $(\mu \mathrm{m})$ & Sa $(\mu \mathrm{m})$ \\
\hline M $_{0}$ & 3.3 & 2.6 \\
M-PVA5 & 4 & 3.2 \\
M-PVA5/CA2 & 4.3 & 3.4 \\
M-PEGML2/PVA5/CA2 & 3.8 & 3 \\
\hline
\end{tabular}

\subsubsection{XPS Analysis}

The XPS test can analyze the elemental composition of the membrane surface. From Figure 5a, it can be observed that $\mathrm{M}_{0}$ has distinct $\mathrm{C} 1 \mathrm{~s}$ and $\mathrm{F} 1 \mathrm{~s}$ peaks at $284.75 \mathrm{eV}$ and $689.29 \mathrm{eV}$. The incomplete air extraction may cause the weak O1s peak at $545.48 \mathrm{eV}$ during the test. The O1's peak at $545.48 \mathrm{eV}$ is significantly enhanced for M-PVA5, M-PVA5/CA2, and M-PEGML2/PVA5/CA2 membranes, which is caused by the deposition of different hydrophilic coatings on the surface of PTFE microfiltration membranes. Meanwhile, the chemical compositions of the different PTFE microfiltration membranes were recorded in Table 3, and the results were in agreement with those obtained by XPS spectroscopy. In order to further reveal the surface chemistry of different microfiltration membranes, we performed a split-peak fit to C1s. From Figure $5 b$, it can be observed that the $C 1$ s of $\mathrm{M}_{0}$ can be divided into two peaks corresponding to $\mathrm{C}-\mathrm{F}$ at $291.9 \mathrm{eV}$ and $\mathrm{C}-\mathrm{C}$ at $284.3 \mathrm{eV}$, respectively. Figure $5 \mathrm{c}$ shows a new peak at $285.6 \mathrm{eV}$ corresponding to $\mathrm{C}-\mathrm{OH}$ in $\mathrm{PVA}$, indicating that PVA is deposited onto the membrane's surface. Figure $5 \mathrm{~d}$ shows a new peak at $288.3 \mathrm{eV}$ corresponding to the ester carbonyl group $(\mathrm{C}=\mathrm{O})$, indicating that PVA and CA crosslinked 
and deposited onto the membrane surface. In Figure 5e, compared with Figure 5d, it can be observed that the proportion of $\mathrm{C}=\mathrm{O}$ area at $288.3 \mathrm{eV}$ has increased, which indicates that PEGML was successfully deposited on the surface of the membrane. The XPS analysis results are consistent with the infrared analysis results.
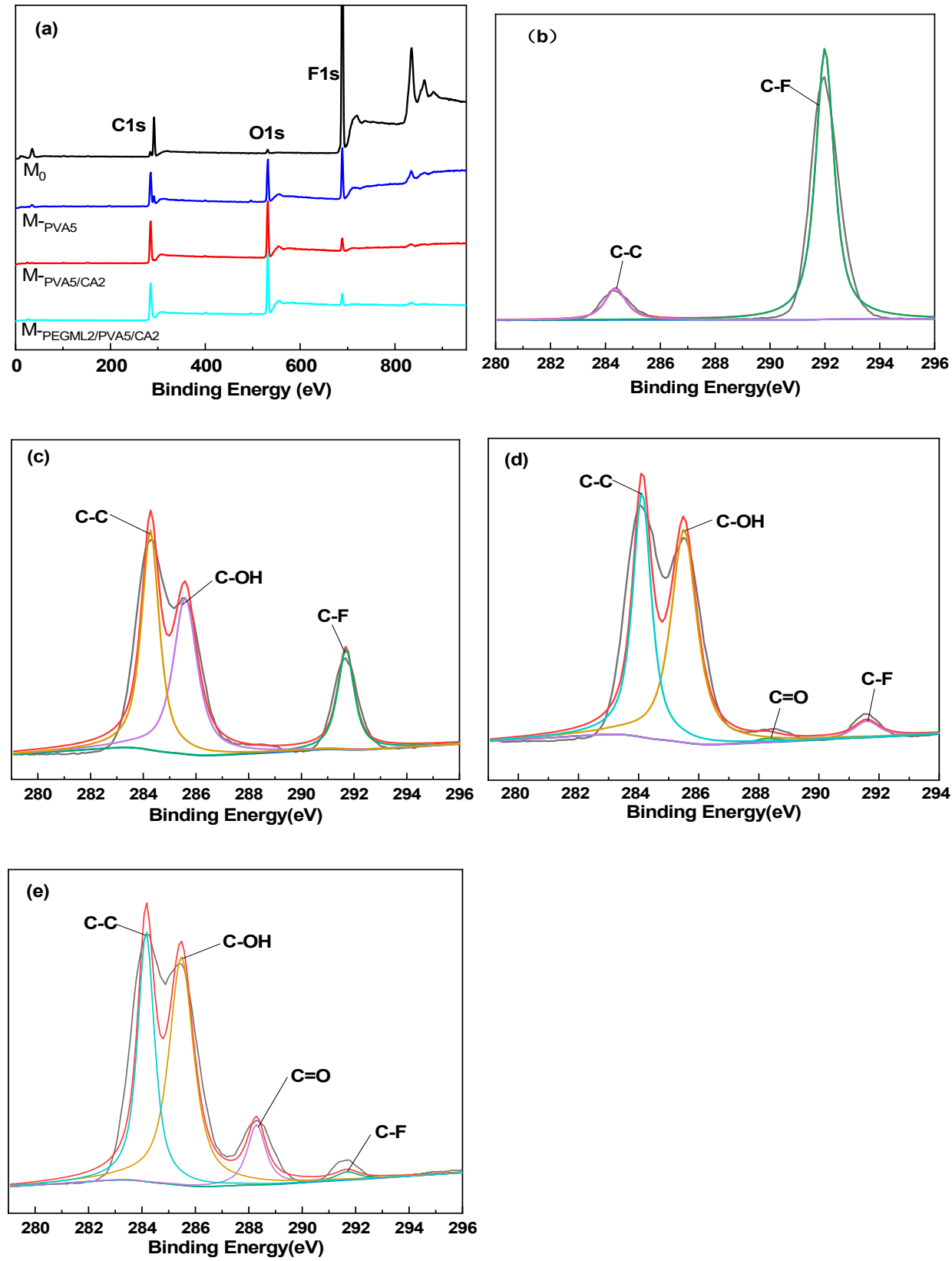

Figure 5. XPS spectra of different PTFE microfiltration membranes (a) and C1s XPS spectra of $\mathrm{M}_{0}(\mathbf{b})$, M-PVA5 (c), M-PVA5/CA2 (d), and M-PEGML2/PVA5/CA2 (e).

Table 3. Surface element composition of different PTFE microfiltration membranes.

\begin{tabular}{cccc}
\hline \multirow{2}{*}{ Samples } & \multicolumn{3}{c}{ Content (\%) } \\
\cline { 2 - 4 } & $\mathbf{C}$ & $\mathbf{F}$ & $\mathbf{O}$ \\
\hline M $_{0}$ & 31.57 & 66.9 & 1.53 \\
M-PVA5 & 58.53 & 19.73 & 21.74 \\
M-PVA5/CA2 & 64.54 & 5.75 & 29.72 \\
M-PEGML2/PVA5/CA2 & 61.7 & 4.89 & 33.4 \\
\hline
\end{tabular}




\subsection{Optimization of Hydrophilic Modification Conditions}

3.2.1. Effect of PEGML Concentration on the Water Contact Angle of PTFE Microfiltration Membrane

As shown in Figure 6, the changes of contact angle on the surface of the PTFE microfiltration membrane after treatment with different concentrations of PEGML solution are shown. The contact angle of the M-PEGML1 microfiltration membrane is $107^{\circ}$, and the surface still shows a hydrophobic state. When the PEGML concentration increased to $2 \mathrm{~g} \cdot \mathrm{L}^{-1}$, the contact angle of the M-PEGML2 microfiltration membrane surface decreased to $80^{\circ}$, and the membrane surface realized the transition from hydrophobic to hydrophilic and water droplets could wet the membrane surface. This is because PEGML can be adsorbed on the surface of the PTFE microfiltration membrane by the forces of van der Waals forces and hydrophobic interactions. Thus, the hydrophilic groups on the PEGML chain segments can enhance the hydrophilicity of the microfiltration membrane surface [31]. At the same time, the surfactant can reduce the surface tension of the liquid, thus allowing water droplets to spread out when they come in contact with the membrane surface, further wetting the membrane surface. When the PEGML concentration was further increased to $4 \mathrm{~g} \cdot \mathrm{L}^{-1}$, the contact angle decreased to $68^{\circ}$, only $12^{\circ}$ compared to $2 \mathrm{~g} \cdot \mathrm{L}^{-1}$ after surfactant pretreatment. However, when the concentration of PEGML increased to $4 \mathrm{~g} \cdot \mathrm{L}^{-1}$, the surfactant attached to the fibers and nodes of the membrane increased significantly. Thus, the membrane pore size decreased, which may not be conducive to the subsequent deposition of PVA/CA hydrophilic coating on the surface of the membrane (Figure 4e). Therefore, in the following crosslinking treatment, the membranes were coated with $2 \mathrm{~g} \cdot \mathrm{L}^{-1}$ PEGML solution.

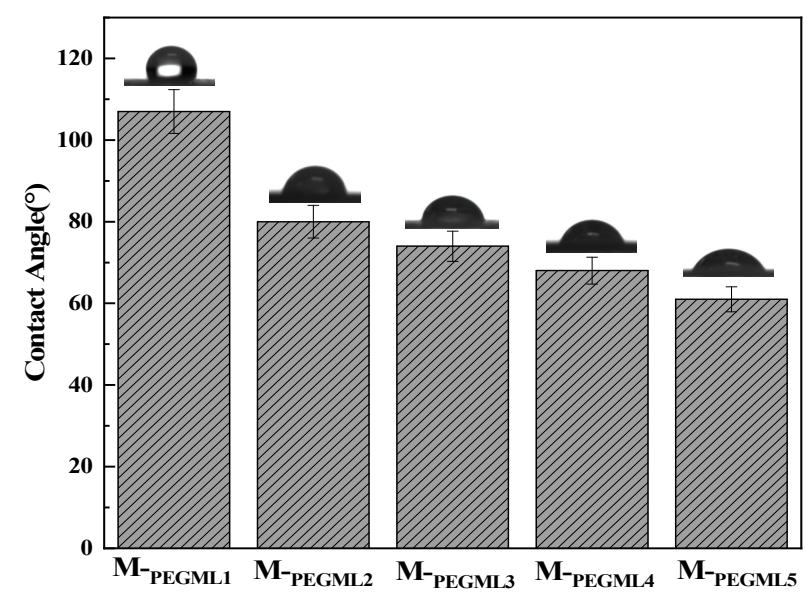

Figure 6. Contact angle of PTFE microfiltration membrane surface after pre-wetting with different concentrations of PEGML.

\subsubsection{Effect of PVA Content on Hydrophilic Properties of PTFE}

Figure 7 shows the results of water flux and water contact angle tests of PTFE microfiltration membranes modified by coating with different concentrations of PVA solution. The contact angle of the membrane surface decreases with the increase in PVA concentration. This is because the higher concentration of PVA increases the hydrophilic hydroxyl groups on the membrane surface; therefore, the hydrolysis contact angle tends to decrease. The water flux of the modified PTFE membrane shows a trend of rising and then falling, which is because the increase in PVA concentration facilitates more hydrophilic groups to attach to the fiber and node surfaces of the membrane, and the hydrophilicity of the membrane surface increases; thus, water flux rises. When the PVA concentration is higher than $5 \mathrm{~g} \cdot \mathrm{L}^{-1}$, the water flux begins to decrease because the further increase in PVA concentration results in some membrane pores being blocked. The average pore size of the PTFE microfiltration membrane decreases, thus resulting in a decrease in water flux. Therefore, the optimal PVA concentration in the modified conditions was $5 \mathrm{~g} \cdot \mathrm{L}^{-1}$. 


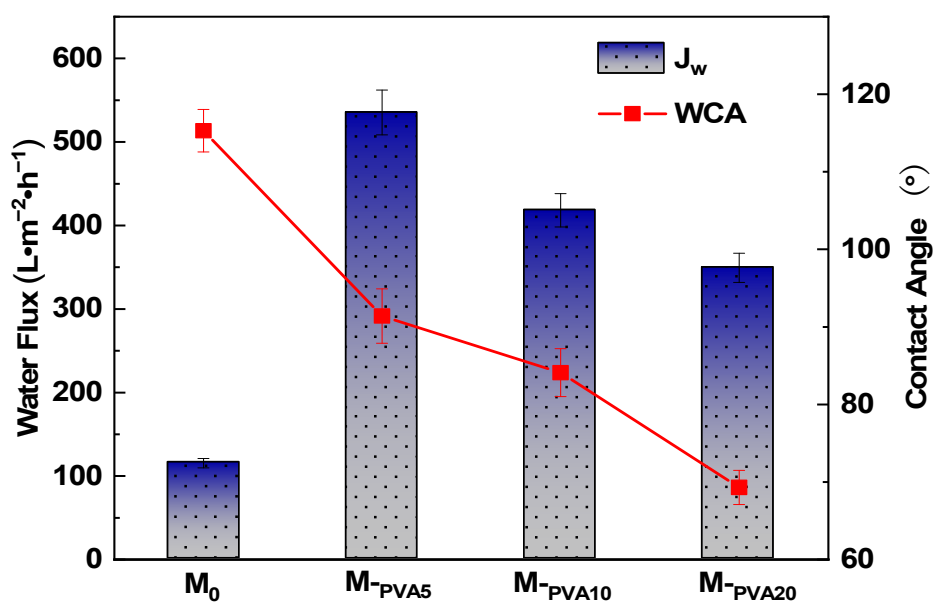

Figure 7. Water flux and water contact angle of PTFE microfiltration membranes coated with different concentrations of PVA solution.

\subsubsection{Effect of Crosslinker Content on the Hydrophilic Properties of PTFE}

In order to enhance the stability of PVA in the aqueous phase, we used CA and PVA for chemical crosslinking. We investigated the relationship between the concentration of $\mathrm{CA}$ and the hydrophilic properties of the modified PTFE microfiltration membrane. The effect of the concentration of CA on the hydrophilic properties of PTFE microfiltration membranes is shown in Figure 8. Water flux increased from $350.6 \mathrm{~L} \cdot \mathrm{m}^{-2} \cdot \mathrm{h}^{-1}$ to $396.9 \mathrm{~L} \cdot \mathrm{m}^{-2} \cdot \mathrm{h}^{-1}$ when the concentration of CA increased from 1 to $2 \mathrm{~g} \cdot \mathrm{L}^{-1}$. Instead, the contact angle increased, and the contact angle increased because the increase in citric acid content consumed more hydrophilic groups hydroxyl groups. Hence, the hydrophilicity of the membrane surface decreased. The increase in water flux may be due to the swelling of the PTFE fibers and the PVA coating attached to the nodes under pure water filtration. The addition of an appropriate amount of citric acid helps enhance the crosslinking density of PVA, reducing the swelling behavior of PVA [34,35]. Therefore, the blockage of the pore size by the dissolved PVA coating is reduced, and flux is increased. At the same time, the increase in cross-linking density makes the cross-linked structure more stable, which also improves the stability of the PVA cross-linked coating in water. However, when the content of CA was further increased, the water flux showed a continuous decrease, and when the content of CA increased to $5 \mathrm{~g} \cdot \mathrm{L}^{-1}$, the water flux was only $140.4 \mathrm{~L} \cdot \mathrm{m}^{-2} \cdot \mathrm{h}^{-1}$. This is because the addition of too much citric acid consumes many hydrophilic groups hydroxyl groups, making the PVA coating significantly less hydrophilic. Therefore, flux decreases, and haptic hydrolysis rises. Therefore, the optimal CA concentration was chosen to be $2 \mathrm{~g} \cdot \mathrm{L}^{-1}$.

\subsection{PTFE Microfiltration Membrane Performance Test}

\subsubsection{Hydrophilic Performance Test}

From Figure $9 \mathrm{a}$, we can observe that the initial contact angle of the $\mathrm{M}_{0}$ is around $120^{\circ}$, and there is no significant change in the contact angle within $150 \mathrm{~s}$. The PTFE surface is strongly hydrophobic, and the unmodified PTFE membrane cannot be wetted by pure water. The initial water contact angle of the surface of M-PVA5/CA2 membrane was $83^{\circ}$, which decreased to $42^{\circ}$ after $150 \mathrm{~s}$ wetting, indicating that the modified membrane has good hydrophilicity. In this case, $\mathrm{M}_{\text {PVA5/CA2 }}$ membrane formed a three-dimensional network structure on the surface of the PTFE membrane by cross-linking of PVA and CA, which enhanced the hydrophilicity of the membrane surface. The M-PEGML2/PVA5/CA2 modified membrane showed that the water droplets were wholly absorbed in $50 \mathrm{~s}$ and the initial contact angle reached about $40^{\circ}$, indicating that the modified membrane surface has excellent wettability. This is due to the deposition of PEGML on the PTFE membrane surface through hydrophobic interactions and encapsulation by PVA/CA gel coating, which further enhances the hydrophilicity of PTFE membranes. Meanwhile, the water 
flux test results in Figure $9 \mathrm{~b}$ showed the same pattern, with the water flux of M-PVA5/CA2 increasing to $261.4 \mathrm{~L} \cdot \mathrm{m}^{-2} \cdot \mathrm{h}^{-1}$, while the water flux of M-PEGML2/PVA5/CA2 further increased to $396.9 \mathrm{~L} \cdot \mathrm{m}^{-2} \cdot \mathrm{h}^{-1}$, which is about three times the original membrane. At the same time, the modified PTFE microfiltration membrane does not require pre-wetting treatment, simplifying the use process and improving separation efficiency. We have compared our work with related work in recent years, and the results are recorded in Table 4 . It can be observed from Table 4 that our modified PTFE microfiltration membrane has excellent water flux similar to other studies. At the same time, our method is simpler and cheaper than other methods. The reagents we use are environmentally friendly. Therefore, the hydrophilic modification method we use is expected to achieve industrial applications.

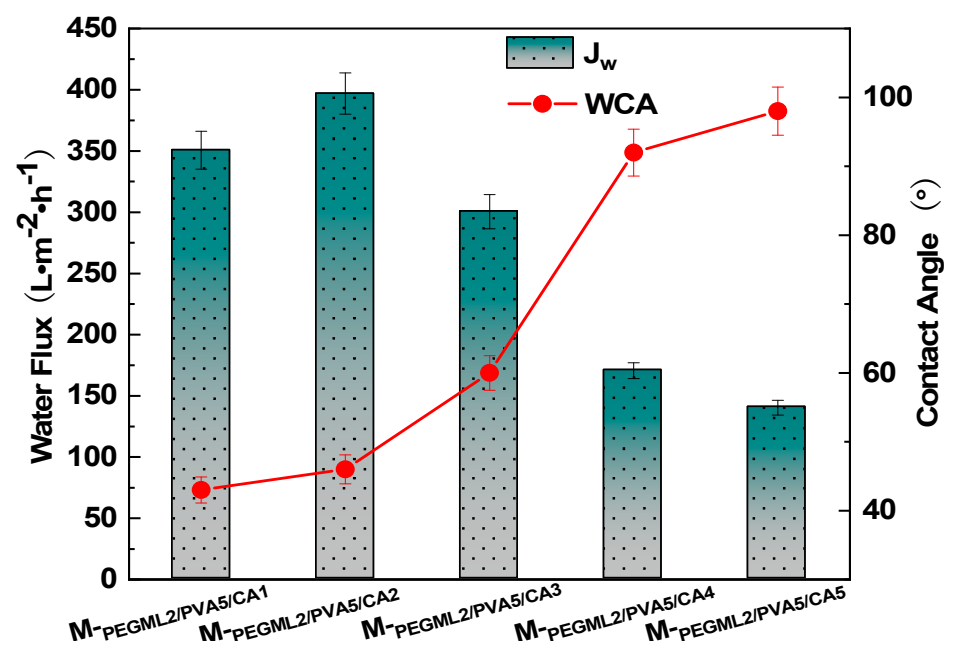

Figure 8. Water flux and water contact angle of PTFE microfiltration membranes modified with different concentrations of CA.
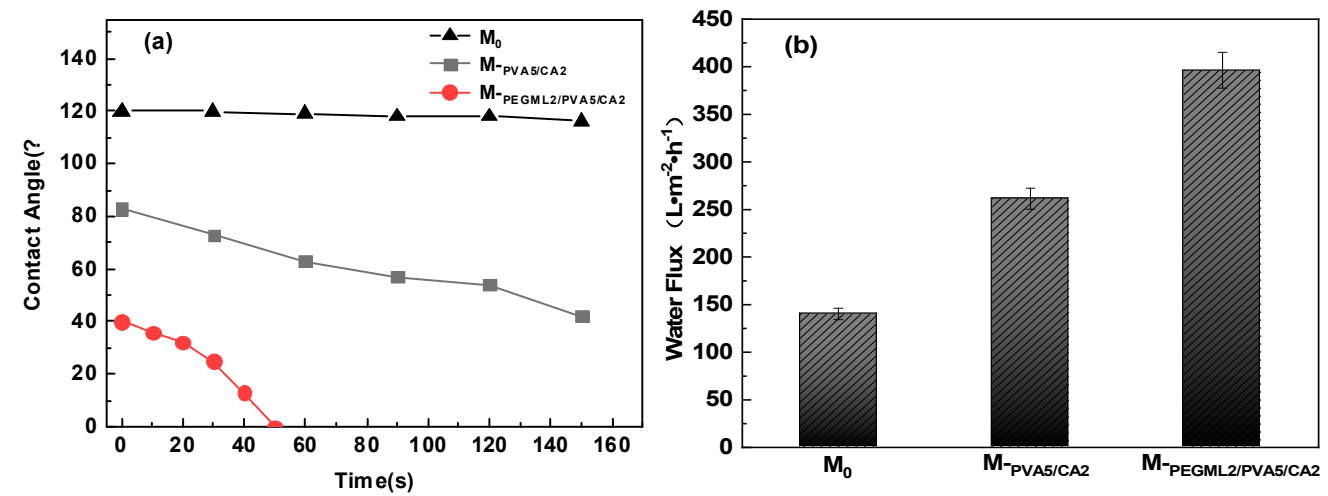

Figure 9. (a) Dynamic contact angle of different PTFE microfiltration membranes; (b) water flux of different PTFE microfiltration membranes (the test pressure is $0.05 \mathrm{Mpa}$ ).

Table 4. Comparison of hydrophilic modification methods of various microfiltration membranes.

\begin{tabular}{|c|c|c|c|c|}
\hline Membrane & $\operatorname{PWF}\left(\mathrm{L} \cdot \mathrm{m}^{-2} \cdot \mathrm{h}^{-1}\right)$ & Operating Pressure (Mpa) & Modification Method & \\
\hline PTFE $(0.22 \mu \mathrm{m})$ & 397 & 0.05 & PEGML/PVA Co-deposition & This work \\
\hline PTFE $(0.5 \mu \mathrm{m})$ & 830 & 0.1 & $\begin{array}{l}\text { Grafting } \mathrm{gC}_{3} \mathrm{~N}_{4} / \mathrm{TiO}_{2} / \mathrm{PAA} \text { after } \\
\text { plasma treatment }\end{array}$ & [36] \\
\hline $\operatorname{PVDF}(0.22 \mu \mathrm{m})$ & 785 & 0.09 & $\mathrm{PDA} / \mathrm{KH} 550 / \mathrm{TiO}_{2}$ Co-deposition & [37] \\
\hline PTFE $(0.2 \mu \mathrm{m})$ & 175 & 0.01 & P(VP-VTES) Crosslinking & [12] \\
\hline PTFE $(0.5 \mu \mathrm{m})$ & 750 & 0.1 & $\begin{array}{l}\text { Grafting } \mathrm{TiO}_{2} / \text { PAA after } \\
\text { plasma treatment }\end{array}$ & [38] \\
\hline
\end{tabular}




\subsubsection{BSA Solution Filtration Performance Test}

The relationship between the normalized flux and time of different PTFE microfiltration membranes is recorded in Figure 10, and 0 min corresponds to the stable pure water flux $J_{W 0}$. The lower FRR and higher DRt of the $\mathrm{M}_{0}$ can be observed in Figure 10, which indicates the poor antifouling ability of the PTFE original membranes. The hydrophobichydrophobic solid interaction between the PTFE membrane surface and proteins makes it difficult to recover the contaminated membrane surface by simple washing [39,40]. Compared to the original PTFE membrane, the M-PVA5/CA2 membrane showed a 9\% increase in flux recovery, a 14\% decrease in flux drop, and a $9 \%$ decrease in irreversible flux drop. This indicates that the BSA molecules attached to the surface of the M-PVA5/CA2 membrane are more easily repelled by water, and its antifouling ability is improved compared to the original membrane. The deposition of PVA/CA cross-linked coating on the membrane surface achieves the transformation of the PTFE microfiltration membrane from hydrophobic to hydrophilic. Thus, the hydrated layer on the membrane surface weakened the hydrophobic interaction between BSA molecules and the PTFE microfiltration membrane, resulting in improved antifouling ability [12]. The flux recovery rate, decline rate, and irreversible flux drop rate of the M-PEGML2/PVA5/CA2 membrane were further improved than compared to the M-PVA5/CA2 membrane. This is because some hydroxyl groups are consumed during the esterification reaction between PVA and CA, resulting in fewer hydrophilic groups in the PVA/CA coating. At the same time, PEGML enhances the hydration capacity of the co-deposited coating. The uniform PVA/CA coated layer makes it easier for water to wet the membrane surface. Therefore, water is more likely to wet the M-PEGML2/PVA5/CA2 membrane surface to form a hydrated layer, thus more easily preventing BSA molecules from coming into contact with the membrane surface. In conclusion, M-PVA5/CA2 and M-PEGML2/PVA5/CA2 modified membranes have superior anti-fouling ability than PTFE. Moreover, we tested the BSA adsorption of different PTFE microfiltration membranes, and the corresponding results were recorded in Table 5. Again, due to the excellent hydrophilic surface of the modified M-PVA5/CA2 and M-PEGML2/PVA5/CA2 microfiltration membranes, their BSA adsorption amounts were significantly lower compared to PTFE.

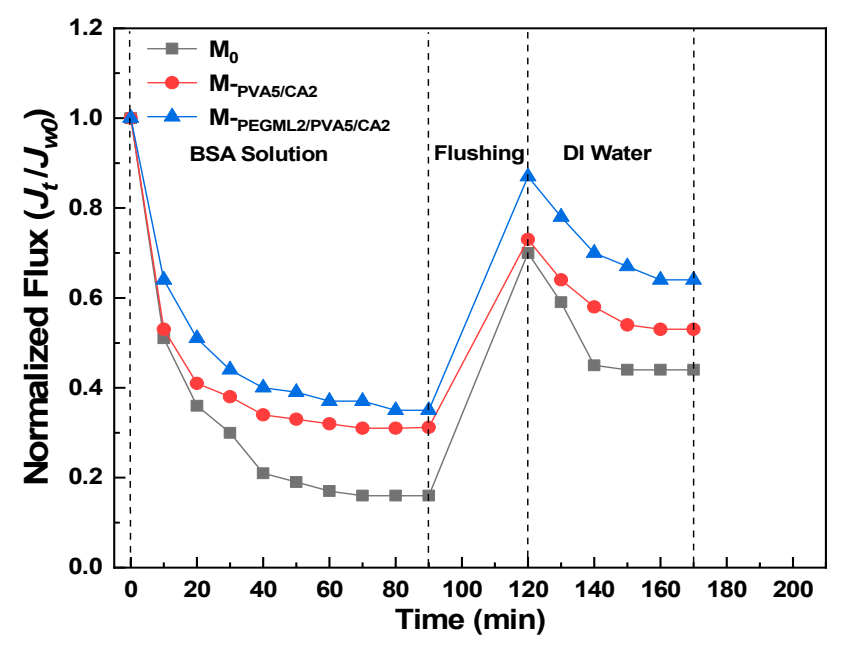

Figure 10. Testing of hydrophilic modified membranes for resistance to BSA adsorption.

Table 5. Antifouling performance parameters of different PTFE microfiltration membranes.

\begin{tabular}{ccccc}
\hline Samples & FRR (\%) & DRt (\%) & DRir (\%) & Adsorption Quantity (g/m $\left.{ }^{\mathbf{2}}\right)$ \\
\hline $\mathrm{M}_{0}$ & 44 & 83 & 56 & 20.94 \\
M-PVA5/CA2 & 53 & 69 & 47 & 6.25 \\
M-PEGML2/PVA5/CA2 & 64 & 65 & 36 & 4.8 \\
\hline
\end{tabular}




\subsubsection{Hydrophilic Coating Stability Test}

In Figure 11a, the water flux of the modified membrane decreases slightly with the increase in the number of washes (four hours per wash) and then stabilizes. The membrane loss of the modified membrane is slight, which indicates that the hydrophilic coating of the modified membrane has good physical stability. This is because the three-dimensional network structure formed by the cross-linking of PVA and CA is deposited and wrapped around the fibers and nodes of the PTFE membrane, which also makes PEGML more stably anchored to the membrane surface. Figure $11 \mathrm{~b}$ shows the water flux test of PTFE microfiltration membranes after $12 \mathrm{~h}$ of immersion in solutions of different $\mathrm{pH}$ values. The flux of $\mathrm{M}_{\text {-PVA5/CA2 }}$ and M-PEGML2/PVA5/CA2 membranes in $\mathrm{pH}=3$ and $\mathrm{pH}=12$ solutions does not drop much compared with the pure water environment, which indicates that these two modified membranes have good stability in these two solutions. The decrease in the flux of M-PEGML2/PVA5/CA2 and M-PVA5/CA2 modified membranes was more dramatic in solutions with $\mathrm{pH}=1$ and $\mathrm{pH}=14$. This is due to the hydrolysis of ester groups in strongly acidic and alkaline environments resulting in the exfoliation of the modified layers [11]. In conclusion, M-PVA5/CA2 and M-PEGML2/PVA5/CA2 microfiltration membranes have good stability in chemical environments ranging from $\mathrm{pH}=3$ to 12 .
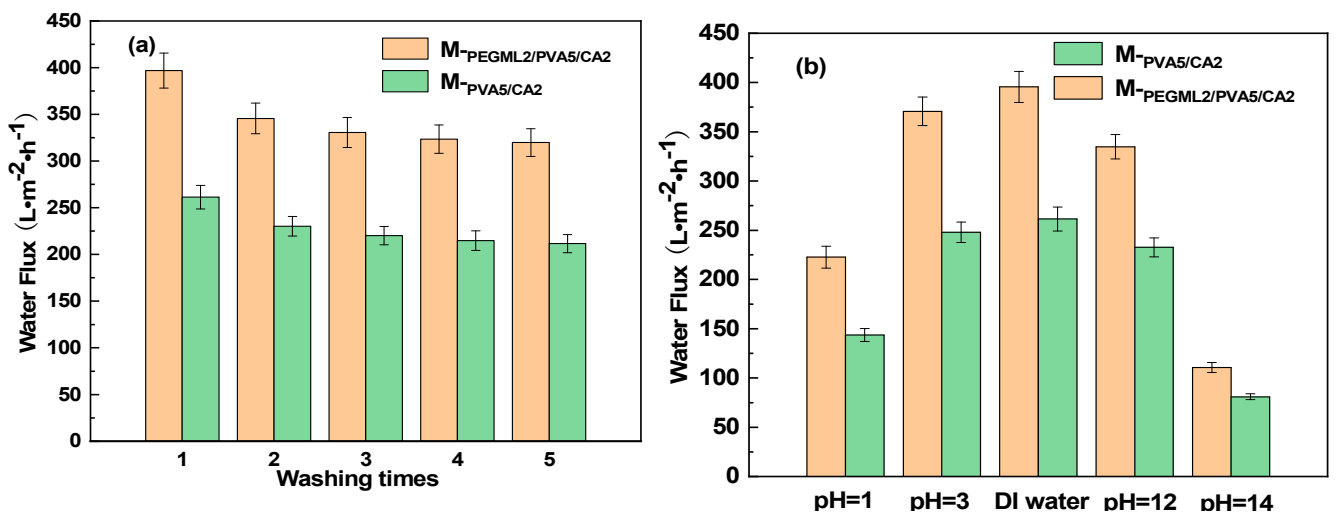

Figure 11. (a) The relationship between the number of cleaning and water flux; (b) water flux testing in different chemical environments.

\section{Conclusions}

In this paper, a PTFE membrane was pretreated by PEGML and then crosslinked by PVA and CA at high temperatures to form a gel coating containing many hydroxyl groups wrapped around the membrane fiber surface to complete hydrophilic modification. XPS, IR, and SEM data showed that crosslinking of PVA and CA occurred and that PEGML and PVA/CA were successfully deposited onto the membrane surface. Due to the hydrophilic coating formed on the surface of the membrane, the water flux of the modified PTFE microfiltration membrane is three times that of the original membrane, and the contact angle drops to $40^{\circ}$. At the same time, it is easier to form a hydration layer on the surface of the hydrophilic modified PTFE membrane, which weakens the interaction between the PTFE microfiltration membrane and hydrophobic contaminants. Therefore, the antifouling ability of the modified PTFE microfiltration membrane has been improved. The modified PTFE microfiltration membrane has good flux stability in pure water and $\mathrm{pH}=3 \sim 12$ chemical environment. This is because the cross-linking of PVA and CA enables the hydrophilic layer to be firmly deposited and wrapped on the fibers and nodes of the PTFE microfiltration membrane. In conclusion, this study achieves the hydrophilic modification of PTFE microfiltration membrane by a low-cost, green, and simple method, which has good application prospects in the practical industry. 
Author Contributions: Data collation, S.X. and W.M.; formal analysis, S.X., W.M. and H.Y.; funding acquisition, W.M., F.G. and C.L.; investigation, S.X. and W.M.; methodology, S.X., W.M., Z.C. and H.Y.; project management, W.M., Z.C. and C.L.; writing-original draft, S.X. and W.M.; writing-reviewing and editing, S.X. and W.M. and F.G. All authors have read and agreed to the published version of the manuscript.

Funding: This research was supported by the National Natural Science Foundation of China (21406017); the Natural Science Foundation of the Jiangsu Higher Institutions of China (18KJA430005); Changzhou Science and Technology Support Plan (Social Development) (CE20205055); the Priority Academic Program Development of Jiangsu Higher Education Institutions (PAPD); the Top-notch Academic Programs Project of Jiangsu Higher Education Institutions (TAPP); Advanced Catalysis and Green Manufacturing Collaborative Innovation Center, Changzhou University; and Postgraduate Research \& Practice Innovation Program of Jiangsu Province (SJCX21_1179).

Institutional Review Board Statement: Not applicable.

Informed Consent Statement: Not applicable.

Acknowledgments: We thatnk the Changzhou Jinchun Environmental Protection Technology Co. for PTFE microfiltration membrane.

Conflicts of Interest: There are no conflict of interest to declare.

\section{References}

1. Li, X.; Shan, H.; Cao, M.; Li, B. Mussel-inspired modification of PTFE membranes in a miscible THF-Tris buffer mixture for oil-in-water emulsions separation. J. Membr. Sci. 2018, 555, 237-249. [CrossRef]

2. Lee, E.-J.; Kim, K.-Y.; Lee, Y.-S.; Nam, J.-W.; Lee, Y.-S.; Kim, H.-S.; Jang, A. A study on the high-flux MBR system using PTFE flat sheet membranes with chemical backwashing. Desalination 2012, 306, 35-40. [CrossRef]

3. Li, C.; He, Z.; Wang, F.; Zhu, H.; Guo, Y.; Chen, M. Laccase-catalyzed homo-polymer of GAL and cross-linking with PEI to enhance hydrophilicity and antifouling property of PTFE flat membrane. Prog. Org. Coat. 2019, 132, 429-439. [CrossRef]

4. Xue, S.; Li, C.; Li, J.; Zhu, H.; Guo, Y. A catechol-based biomimetic strategy combined with surface mineralization to enhance hydrophilicity and anti-fouling property of PTFE flat membrane. J. Membr. Sci. 2017, 524, 409-418. [CrossRef]

5. Feng, S.; Zhong, Z.; Wang, Y.; Xing, W.; Drioli, E. Progress and perspectives in PTFE membrane: Preparation, modification, and applications. J. Membr. Sci. 2018, 549, 332-349. [CrossRef]

6. Liu, H.; Liu, G.; Zhang, M.; Zhao, H.; Jiang, Y.; Gao, J. Rapid preparation of Tannic acid (TA) based zwitterionic nanofiltration membrane via a multiple layer-by-layer (mLBL) assembly strategy for enhanced antifouling performance. Sep. Purif. Technol. 2020, 253, 117519. [CrossRef]

7. Shahkaramipour, N.; Tran, T.N.; Ramanan, S.; Lin, H.Q. Membranes with Surface-Enhanced Antifouling Properties for Water Purification. Membranes 2017, 7, 13. [CrossRef] [PubMed]

8. Wang, S.; Li, J.; Suo, J.; Luo, T. Surface modification of porous poly(tetrafluoraethylene) film by a simple chemical oxidation treatment. Appl. Surf. Sci. 2010, 256, 2293-2298. [CrossRef]

9. Liu, K.; Lei, J.; Zheng, Z.; Zhu, Z.; Liu, S. The hydrophilicity improvement of polytetrafluoroethylene by Ar plasma jet: The relationship of hydrophilicity, ambient humidity and plasma parameters. Appl. Surf. Sci. 2018, 458, 183-190. [CrossRef]

10. Hidzir, N.M.; Lee, Q.; Hill, D.J.T.; Rasoul, F.; Grondahl, L. Grafting of Acrylic Acid-co-Itaconic Acid onto ePTFE and Characterization of Water Uptake by the Graft Copolymers. J. Appl. Polym. Sci. 2015, 132, 41482. [CrossRef]

11. Li, C.; Wang, J.; Luo, Y.; Wang, F.; Zhu, H.; Guo, Y. One-bath two step method combined surface micro/nanostructures treatment to enhance antifouling and antibacterial property of PTFE flat membrane. J. Taiwan Inst. Chem. E 2019, 96, 639-651. [CrossRef]

12. Liu, W.; Lin, H.; Wang, J.; Han, Q.; Liu, F. Polytetrafluoroethylene (PTFE) hollow fibers modified by hydrophilic crosslinking network $(\mathrm{HCN})$ for robust resistance to fouling and harsh chemical cleaning. J. Membr. Sci. 2021, 630, 119301. [CrossRef]

13. Song, H.M.; Yu, H.W.; Zhu, L.J.; Xue, L.X.; Wu, D.C.; Chen, H. Durable hydrophilic surface modification for PTFE hollow fiber membranes. React. Funct. Polym. 2017, 114, 110-117. [CrossRef]

14. Wang, J.; Li, C.; Wang, F.; Yu, B.; Luo, Y.; Zeng, H.; Zhu, H. Hydrophilic modification of PTFE microfiltration flat membrane by crosslinking OCMCS-PEI to enhance anti-fouling property. Prog. Org. Coat. 2019, 135, 565-573. [CrossRef]

15. Bell, D.J.; Ludwanowski, S.; Luken, A.; Sarikaya, B.; Walther, A.; Wessling, M. Hydrogel membranes made from crosslinked microgel multilayers with tunable density. J. Membr. Sci. 2021, 620, 118912. [CrossRef]

16. Topuz, F.; Holtzl, T.; Szekely, G. Scavenging organic micropollutants from water with nanofibrous hypercrosslinked cyclodextrin membranes derived from green resources. Chem. Eng. J. 2021, 419, 129443. [CrossRef]

17. Abdulhamid, M.A.; Hardian, R.; Szekely, G. Waltzing around the stereochemistry of membrane crosslinkers for precise molecular sieving in organic solvents. J. Membr. Sci. 2021, 638, 119724. [CrossRef] 
18. Chisca, S.; Bettahalli, N.M.S.; Musteata, V.E.; Vasylevskyi, S.; Hedhili, M.N.; Abou-Hamad, E.; Karunakaran, M.; Genduso, G.; Nunes, S.P. Thermal treatment of hydroxyl functionalized polytriazole and its effect on gas transport: From crosslinking to carbon molecular sieve. J. Membr. Sci. 2022, 642, 119963. [CrossRef]

19. Gu, Y.; Zhang, B.; Fu, Z.; Li, J.; Yu, M.; Li, L.; Li, J. Poly (vinyl alcohol) modification of poly(vinylidene fluoride) microfiltration membranes for oil/water emulsion separation via an unconventional radiation method. J. Membr. Sci. 2021, 619, 118792. [CrossRef]

20. Li, C.; Zhang, H.; Wang, F.; Zhu, H.; Guo, Y.; Chen, M. PVA and CS cross-linking combined with in situ chimeric $\mathrm{SiO}_{2}$ nanoparticle adhesion to enhance the hydrophilicity and antibacterial properties of PTFE flat membranes. RSC Adv. 2019, 9, 19205-19216. [CrossRef]

21. Wang, K.; Hou, D.; Wang, J.; Wang, Z.; Tian, B.; Liang, P. Hydrophilic surface coating on hydrophobic PTFE membrane for robust anti-oil-fouling membrane distillation. Appl. Surf. Sci. 2018, 450, 57-65. [CrossRef]

22. Wang, S.Y.; Ren, J.L.; Li, W.Y.; Sun, R.C.; Liu, S.J. Properties of polyvinyl alcohol/xylan composite films with citric acid. Carbohydr. Polym. 2014, 103, 94-99. [CrossRef]

23. Biswal, N.R.; Paria, S. Wetting of TX-100 and lgepal CO-630 Surfactants on a PTFE Surface. Ind. Eng. Chem. Res. 2011, 50, 6138-6145. [CrossRef]

24. Zdziennicka, A.; Janczuk, B.; Wojcik, W. The wettability of polytetrafluoroethylene by aqueous solutions of sodium dodecyl sulfate and propanol mixtures. J. Colloid Interface Sci. 2005, 281, 465-472. [CrossRef]

25. Szymczyk, K. Wetting and Adsorption Properties of Aqueous Solutions of Ternary Mixtures of Hydrocarbon and Fluorocarbon Nonionic Surfactants in PTFE-Solution-Air Systems. Ind. Eng. Chem. Res. 2013, 52, 9106-9114. [CrossRef]

26. Chaudhuri, R.G.; Sunayana, S.; Paria, S. Wettability of a PTFE surface by cationic-non-ionic surfactant mixtures in the presence of electrolytes. Soft Matter 2012, 8, 5429-5433. [CrossRef]

27. Chen, X.R.; Su, Y.; Shen, F.; Wan, Y.H. Antifouling ultrafiltration membranes made from PAN-b-PEG copolymers: Effect of copolymer composition and PEG chain length. J. Membr. Sci. 2011, 384, 44-51. [CrossRef]

28. Ding, X.L.; Kang, T.; Zhao, H.Y.; Wang, Q.; Zhang, Y.Z.; Kang, G.D. Antifouling behavior on the linear suspension PEG-based surface and two-end-linked PEG-based surface of composite nanofiltration membranes via two-step interfacial polymerization. Desalination Water Treat. 2019, 144, 9-25. [CrossRef]

29. Khoiroh, I.; Lee, S.Y.; Pirdashti, M.; Lee, M.J. Insight into structural properties of polyethylene glycol monolaurate in water and alcohols from molecular dynamics studies. RSC Adv. 2020, 10, 21760-21771. [CrossRef]

30. Liu, S.; Cui, S.; Qin, Z.; Zhang, X.; Zhao, Y.; Zhao, Y.; Guo, H. Modification of a Poly(tetrafluoroethylene) Porous Membrane to Superhydrophilicity with Improved Durability. Chem. Eng. Technol. 2019, 42, 1027-1036. [CrossRef]

31. Shafiei, M.; Hajian, M. Poly(vinyl butyral)/zeolitic imidazole framework-8/poly(vinyl alcohol) thin-film nanocomposite nanofiltration membrane: Synthesis and characterization. Iran Polym. J. 2019, 28, 659-672. [CrossRef]

32. Sabzi, M.; Afshari, M.J.; Babaahmadi, M.; Shafagh, N. pH-dependent swelling and antibiotic release from citric acid crosslinked poly(vinyl alcohol) (PVA)/nano silver hydrogels. Colloids Surf. B 2020, 188, 110757. [CrossRef] [PubMed]

33. Ghorpade, V.S.; Dias, R.J.; Mali, K.K.; Mulla, S.I. Citric acid crosslinked carboxymethylcellulose-polyvinyl alcohol hydrogel films for extended release of water soluble basic drugs. J. Drug Deliv. Sci. Technol. 2019, 52, 421-430. [CrossRef]

34. Wang, J.Q.; Dai, Q.L.; Si, R.Z.; Guo, S.C. Investigation of properties and performances of Polyvinyl Alcohol (PVA) fiber-reinforced rubber concrete. Constr. Build. Mater. 2018, 193, 631-642. [CrossRef]

35. Popescu, M.C. Structure and sorption properties of CNC reinforced PVA films. Int. J. Biol. Macromol. 2017, 101, 783-790. [CrossRef] [PubMed]

36. Huisman, I.H.; Pradanos, P.; Hernandez, A. The effect of protein-protein and protein-membrane interactions on membrane fouling in ultrafiltration. J. Membr. Sci. 2000, 179, 79-90. [CrossRef]

37. Zhou, R.; Ren, P.F.; Yang, H.C.; Xu, Z.K. Fabrication of antifouling membrane surface by poly(sulfobetaine methacrylate)/polydopamine co-deposition. J. Membr. Sci. 2014, 466, 18-25. [CrossRef]

38. Chi, L.N.; Qian, Y.J.; Guo, J.Q.; Wang, X.Z.; Arandiyan, H.; Jiang, Z. Novel g- $\mathrm{C}_{3} \mathrm{~N}_{4} / \mathrm{TiO}_{2} /$ PAA/PTFE ultrafiltration membrane enabling enhanced antifouling and exceptional visible-light photocatalytic self-cleaning. Catal. Today 2019, 335, 527-537. [CrossRef]

39. Shi, H.; He, Y.; Pan, Y.; Di, H.; Zeng, G.; Zhang, L.; Zhang, C. A modified mussel-inspired method to fabricate TiO 2 decorated superhydrophilic PVDF membrane for oil/water separation. J. Membr. Sci. 2016, 506, 60-70. [CrossRef]

40. Qian, Y.; Chi, L.; Zhou, W.; Yu, Z.; Zhang, Z.; Zhang, Z.; Jiang, Z. Fabrication of $\mathrm{TiO}_{2}$-modified polytetrafluoroethylene ultrafiltration membranes via plasma-enhanced surface graft pretreatment. Appl. Surf. Sci. 2016, 360, 749-757. [CrossRef] 